\title{
Ceramic Hydroxyapatite Foam as a New Material for Bisphenol A Removal from Contaminated Water
}

\author{
Hamza. Khallok ${ }^{1,2, *}$, Mohamed. Zbair ${ }^{2,3, *}$, Satu.Ojala ${ }^{2}$, Kaisu. Ainassaari ${ }^{2}$, Rachid. Brahmi ${ }^{4}$, Riitta L. Keiski ${ }^{2}$, \\ Zineb. Hatim ${ }^{1}$ \\ ${ }^{1}$ Team of Energy, Materials, and Environment, Department of Chemistry, Faculty of Sciences, University Chouaib Doukkali, El Jadida, \\ Morocco, \\ ${ }^{2}$ Environmental and Chemical Engineering, Faculty of Technology, P.O. Box 4300, FI-90014, University of Oulu, Finland. \\ ${ }^{3}$ Laboratory of Catalysis and Corrosion of Materials (LCCM), Department of Chemistry, Faculty of Sciences of El Jadida, University of \\ Chouaïb Doukkali, BP.20, 24000 El Jadida, Morocco. \\ ${ }^{4}$ Laboratory of Coordination and Analytical Chemistry (LCCA), University Chouaïb Doukkali, El Jadida -Morocco.
}

*Corresponding authors: khallok.hamza76@gmail.com; zbair.mohamed@gmail.com

\section{Abstract}

Ceramic hydroxyapatite foam (CF-HAP) was prepared by combining slip-casting and foaming methods.

The prepared CF-HAP was characterized by scanning electron microscopy (SEM); physisorption of $\mathrm{N}_{2}$, Fourier transforms infrared spectroscopy (FTIR), and X-ray diffraction (XRD). The results of the specific surface area and SEM analyses revealed that the used shaping method provides CF-HAP with a wide range of porosity including macro and mesopores. Based on FTIR and XRD analyses, the CF-HAP is similar to pure well-crystallized hydroxyapatite. The adsorption results revealed that $94 \%$ of the BPA with a concentration of $(40 \mathrm{mg} / \mathrm{L})$ was effectively removed from the water and that the maximum adsorption capacity was higher in acidic than in basic medium. The thermodynamic studies indicated that the adsorption reaction was spontaneous and endothermic in nature. The adsorption capacity increased with the temperature and the BPA is chemisorbed on the ceramic foam. The isotherm data fitted slightly better with the Liu than with the Freundlich and Langmuir models suggesting that the adsorption was homogeneous and occurred only in the monolayer. The adsorption process depends largely on the BPA concentration and the results fitted well with the pseudo-first-order model. This confirms that the interaction between the BPA and the CF-HAP was mainly chemical in nature. The FTIR analysis of the used and fresh CF-HAP showed that all the hydroxyl and phosphorus bands characteristic of the hydroxyapatite shifted after adsorption of Bisphenol- A. This suggests that the adsorption of BisphenolA occurred in the sites of the Hydroxyapatite. Therefore, it can be concluded that the CF-HAP has the potential to be used as an adsorbent for wastewater treatment and purification processes.

Keywords: Ceramic foam, Hydroxyapatite, Bisphenol A, Adsorption, Water treatment 
Due to the growth of industrial activities, the natural resources essential for life are becoming more and more polluted. This contamination from industrial sources includes heavy metals, salts, detergents, pharmaceutical and dyes, and some other organic matters (Salah et al. 2014; Kakoi et al. 2016; Noukeu et al. 2016).

Some of the organics and pharmaceutical compounds are classified as endocrine-disrupting compounds (EDCs) (Zacharewski et al 1998). It is widely recognized that the EDCs can affect the function of the endocrine system in different ways, for instance, it can mimic or block a hormonal function causing an over or underproduction of hormones (Kapelewska et al. 2016). EDCs can be classified as natural compounds, pharmaceuticals, and industrial chemicals such as alkyl phenols and Bisphenol A (Gu et al. 2016).

Bisphenol-A has been mainly used in the plastics industry as a polycarbonate plasticizer. The Polycarbonate is used in food containers such as recyclable bottles, baby bottles, tableware (plates and cups) as well as containers for storage. It is also used in the manufacturing of coatings or protective films covering the cans and tanks for receiving food and drinks. However, BPA presents a danger to human health and to the environment, if it is released in wastewater or in the drinking water. BPA molecules can reach the environment during the manufacturing process, incomplete water treatment, or by leaching from the landfills and materials containing the substance ( Im and Löffler 2016).

BPA is commonly found in the bodies of a large majority of the population, irrespective of age, and especially in children (Becker et al. 2009). However, BPA toxicity, ecotoxicity, and the acceptable daily intake are still discussed (Beronius et al. 2010) and has been studied with laboratory lab rats, for its effects on the brain functions, and on the reproduction capacity (Authority 2010; Huang et al. 2012).

The treatment of BPA with reverse osmosis (Yüksel et al. 2013), advanced oxidation processes (Umar et al. 2013), membrane bioreactors, and adsorption (Wang et al. 2015, 2018; Zbair et al. 2018b, a; Zielinska et al. 2018) have been studied lately. Adsorption is known to be an effective and fast-growing technology with low cost compared to the other processes (TSAI 2006; Dehghani et al. 2016). Different classes of materials such as clays (Aguiar et al. 2017), hybrid fibers (Zhao et al. 2017), and activated carbons (Bhatnagar and Anastopoulos 2017; Elouahli et al. 2018; Zbair et al. 2019) can be utilized as adsorbents. Despite using these materials, it is still a challenge to design new materials that have high adsorption capacity and rate as well as minimal environmental impact. Some studies have focused on the use of Hydroxyapatite $\left(\mathrm{Ca}_{10}\left(\mathrm{PO}_{4}\right)_{6} \mathrm{OH}_{2}, \mathrm{HAP}\right)$, which is a biocompatible material with significant importance (Achelhi et al. 2010; Ronan and Kannan 2017) in tissue and dental engineering, and in drug delivery (Oliveira and Mansur 2007; Kantharia et al. 2014). It has been reported that hydroxyapatite is an efficient adsorbent material due to its ion-exchange ability and reactive surface. HAP has been used in the removal 
of heavy metals and organic pollutants from water (Lin et al. 2009; Mavropoulos et al. 2011; Kongsri et al. 2013; Mourabet et al. 2015; Pereira et al. 2020). However, the adsorption capacity and, in particular, the adsorption rate remains relatively low for most of the HAP materials when used in powder form (Ciobanu et al. 2009; Lin et al. 2009). It has been reported that the most important characteristics for better adsorption materials are the possibility of having a wide range of pore structure in terms of size, morphology, and quantity as well as the ability to be easily recovered after the adsorption process for further regeneration and reuse (Inagaki 2009; Inagaki and Kang 2014). Therefore, this work will focus on the preparation of a hydroxyapatite foam and its utilization as an adsorbent for BPA removal.

\section{Materials and methods}

\subsection{Preparation of the HAP ceramic foam}

The HAP foam (CF-HAP) was prepared by a combination of the direct foaming and the slip-casting techniques using an aqueous suspension of the sintered HAP powder and egg white as a pore promoter following the procedure described in our previous work (Khallok et al. 2019). The obtained foam was poured into a silicone cylindrical mold $\left(3 \mathrm{~cm}\right.$ in diameter and $0.5 \mathrm{~cm}$ in high) and dried first at $80^{\circ} \mathrm{C}$ for one hour and then at $105^{\circ} \mathrm{C}$ for $24 \mathrm{~h}$. The dried CF-HAP was calcined first at $600^{\circ} \mathrm{C}$ and then at $1200^{\circ} \mathrm{C}$ for further consolidation of the structure.

\subsection{Adsorption experiments}

Adsorption batch experiments were conducted in a shaker at $200 \mathrm{rpm}$. In the kinetic experiments, 150 $\mathrm{mg}$ of ceramic foam was placed into flasks containing $200 \mathrm{~mL}$ of BPA solution with different initial BPA concentrations $(20,30$, and $40 \mathrm{mg} / \mathrm{L})$ without $\mathrm{pH}$ adjustment. Adsorption was carried out at room temperature for 3 hours. The effect of $\mathrm{pH}$ was studied from 2 to 12 with an initial BPA concentration of $40 \mathrm{mg} / \mathrm{L}$ at room temperature. The basic solutions were obtained using $0.1 \mathrm{M} \mathrm{NaOH}$ and acidic medium using $0.1 \mathrm{M} \mathrm{HCl}$. Isotherm studies were conducted by varying the initial concentration from 10 to 50 $\mathrm{mg} / \mathrm{L}$ at room temperature, $303 \mathrm{~K}$, and $313 \mathrm{~K}$ at the optimized $\mathrm{pH}$. After the equilibrium was attained, the samples were filtered, and immediately analyzed using a Shimadzu 1800 UV-vis spectrophotometer at maximum absorbance wavelength $(\lambda \max )$ of $276 \mathrm{~nm}$.

\subsection{Regeneration}

The BPA-laden ceramic foam was regenerated using $40 \mathrm{~mL}$ of ethanol. Ethanol and the used ceramic foam were agitated at room temperature for 4 hours. Then, the ceramic foam was recovered by filtration and dried at $105{ }^{\circ} \mathrm{C}$. Adsorption and regeneration cycles were repeated 3 times.

\subsection{Measurement of $\mathrm{pH}_{\mathrm{pzc}}$}


112 A mixture of $100 \mathrm{mg}$ of the CF-HAP in $100.0 \mathrm{~mL}$ of $0.01 \mathrm{M} \mathrm{KNO}_{3}$ solution is shaken for 60 minutes at 113 room temperature. The initial $\mathrm{pH}$ values $\left(\mathrm{pH}_{0}\right)$ are adjusted in the range of 2.5-9.5 using $0.1 \mathrm{M} \mathrm{KOH}$ or $1140.1 \mathrm{M} \mathrm{HNO}_{3}$ solutions. After equilibration, the $\mathrm{pH}$ values are measured once again $\left(\mathrm{pH}_{\mathrm{f}}\right)$, and the value of $\mathrm{pH}_{\mathrm{pzc}}$ (point of zero charges) is determined from the $\Delta \mathrm{pH}=\mathrm{f}\left(\mathrm{pH}_{0}\right)$ plot $\left(\Delta \mathrm{pH}=\mathrm{pH}_{0}-\mathrm{pH}_{\mathrm{f}}\right) \cdot \mathrm{pH}_{\mathrm{pzc}}$ is 116 the $\mathrm{pH}_{0}$ value when $\Delta \mathrm{pH}=0$.

\subsection{Modeling}

The model parameters of BPA adsorption kinetics and adsorption isotherm were calculated by the nonlinear regression method. All equations and models used in this study are listed in the Table 1:

Table 1 Equations and models used for the adsorption study

\begin{tabular}{|c|c|c|c|}
\hline Removal & Adsorption capacity (Wang J et al. 1998) & $\mathbf{Q}_{\mathrm{e}, \mathrm{t}}=\frac{\left(\mathbf{C}_{0}-\mathbf{C}_{\mathrm{e}}\right) \times \mathbf{V}}{\mathbf{m}}$ & (1) \\
\hline capacity & Removal efficiency (Narwade VN et al. 2017) & $\mathbf{R} \%=\left(\frac{\mathrm{C}_{0}-\mathrm{C}_{\mathrm{e}}}{\mathrm{C}_{0}}\right) \times 100$ & (2) \\
\hline \multirow{3}{*}{ Kinetic models } & Pseudo-first-order (PFO) kinetics (Tran HN et al. 2017) & $Q_{\mathrm{t}}=Q_{\mathrm{cal}}\left(1-\exp ^{\mathrm{K} 1 \mathrm{t}}\right)$ & (3) \\
\hline & $\begin{array}{l}\text { Pseudo-second-order (PSO) kinetics (McKay G 1999; Tran HN et al. } \\
\text { 2017) }\end{array}$ & $\mathbf{Q}_{\mathrm{t}}=\frac{\left(\mathbf{K}_{2} \mathbf{Q}_{\mathrm{cal}}^{2} \mathbf{t}\right)}{\left(\mathbf{1}+\mathbf{K}_{2} \mathbf{Q}_{\mathrm{cal}} \mathbf{t}\right)}$ & (4) \\
\hline & Intra particle diffusion (PID) (Weber W.J. and Morris 1963) & $Q_{t}=K_{i p} t^{\frac{1}{2}}+C$ & (5) \\
\hline \multirow{3}{*}{ Isotherm models } & Langmuir isotherm (Langmuir I 1916) & $Q_{e}=\frac{Q_{L} K_{L} C_{e}}{1+K_{L} C_{e}}$ & (6) \\
\hline & Freundlich isotherm (Freundlich H 1907) & $Q_{e}=K_{f} C_{e}^{\frac{1}{n}}$ & (7) \\
\hline & Liu isotherm (Saucier C et al. 2015) & $\mathbf{Q}_{\mathrm{e}}=\frac{\mathbf{Q}_{\mathrm{Li}} \cdot\left(\mathrm{K}_{\mathrm{g}} \cdot \mathrm{C}_{\mathrm{e}}\right)^{\mathrm{n}_{\mathrm{L}}}}{1+\left(\mathrm{K}_{\mathrm{g}} \cdot \mathrm{C}_{\mathrm{e}}\right)^{\mathrm{n}_{\mathrm{L}}}}$ & (8) \\
\hline
\end{tabular}

Gibbs free energy (Anastopoulos I and Kyzas GZ 2016; Ghosal PS $\quad \Delta \mathbf{G}^{\circ}=-\mathbf{R T I n K}_{\mathbf{c}}$

Thermodynamic models and Gupta AK 2017; Lima EC et al. 2019)

Van't Hof equation (Anastopoulos I and Kyzas GZ 2016; Ghosal

PS and Gupta AK 2017; Lima EC et al. 2019)

$$
\operatorname{LnK}_{c}=\frac{\Delta \mathbf{S}^{\circ}}{\mathbf{R}}-\frac{\Delta \mathbf{H}^{\circ}}{\mathbf{R T}}
$$

Where :

- $\mathrm{C}_{0}, \mathrm{C}_{\mathrm{e}}$ is the initial and the equilibrium concentration of pollutant (mg/L).

- $\mathrm{m}(\mathrm{g})$ : is the weight of adsorbent.

- $\mathrm{V}(\mathrm{L})$ : is the volume of the solution.

- $\mathrm{Q}_{\text {cal }}(\mathrm{mg} / \mathrm{g})$ and $\mathrm{Q}_{\mathrm{t}}(\mathrm{mg} / \mathrm{g})$ are the adsorbed amounts at equilibrium and time $\mathrm{t}$ for the Pseudo first order model. 
- $\mathrm{K}_{1}\left(\mathrm{~min}^{-1}\right)$, and $\mathrm{K}_{2}$ (g/mg.min) are the rate constants of the pseudo first and pseudo second order models respectively.

- $\mathrm{K}_{\mathrm{ip}}\left(\mathrm{mg} / \mathrm{g} \cdot \mathrm{min}^{-1 / 2}\right)$ and $\mathrm{C}(\mathrm{mg} / \mathrm{g})$ are the rate coefficient and the thickness of the boundary layer for the Intra particle diffusion model.

- $\mathrm{K}_{\mathrm{L}}(\mathrm{L} / \mathrm{mg})$ and $\mathrm{Q}_{\mathrm{L}}(\mathrm{mg} / \mathrm{g})$ are the adsorption coefficient and the maximum adsorption capacity of Langmuir model.

- $\mathrm{K}_{\mathrm{f}}(\mathrm{mg} / \mathrm{g})(\mathrm{L} / \mathrm{mg})^{1 / \mathrm{n}}$ and $\mathrm{n}$ are the adsorption coefficient and the intensity of adsorption of Freundlich model.

- $\mathrm{K}_{\mathrm{g}}(\mathrm{L} / \mathrm{mg}), \mathrm{n}_{\mathrm{L}}$ and $\mathrm{Q}_{\mathrm{Li}}(\mathrm{mg} / \mathrm{g})$ : are the equilibrium constant, the exponent and the maximum adsorption capacity for Liu model.

- $\Delta \mathrm{G}^{\circ}(\mathrm{Kj} / \mathrm{mol})$ is the Gibbs free energy change, $\mathrm{K}_{\mathrm{c}}$ (dimensionless) is the adsorption equilibrium constant, $\mathrm{R}$ : gas constant, $\mathrm{T}$ :

Temperature $(\mathrm{K}), \Delta \mathrm{S}^{\circ}(\mathrm{Kj} / \mathrm{mol}), \Delta \mathrm{H}^{\circ}(\mathrm{Kj} / \mathrm{mol})$ are the entropy change and the enthalpy change.

\subsection{Characterization of the HAP foam}

The Infrared Spectra of the obtained and used CF-HAP were recorded on a Fourier Transform Spectrometer (SHIMADZU FTIR-8400S) with a resolution of $4 \mathrm{~cm}^{-1}$ and 100 scans. The measurement range was 400 to $4000 \mathrm{~cm}^{-1}$.

The crystalline phases of the foam were identified using the X-ray diffraction (Diffractometer BRUKER D8 ADVANCED) with Copper $\mathrm{K} \alpha$ radiation $(\lambda=1.5406 \mathrm{~nm})$ produced at $50 \mathrm{kV}$ and $20 \mathrm{~mA}$. The diffractograms were scanned with the $2 \theta$ range of $05-70^{\circ}$ using a step size of $0.02^{\circ}$ and a step time of 30 s. Crystallographic identification was accomplished by comparing the experimental XRD patterns to standards compiled by the joint committee on powder diffraction standards (JCPDS \# 00-009-0432). The porous microstructure of the CF-HAP was examined using a Scanning Electron Microscope ((SEM) Carl Zeiss EVO50 XPV +Röntec X-flash detector type 1106).

The $\mathrm{N}_{2}$ adsorption-desorption isotherms of the CF-HAP were recorded using the ASAP 2020 instrument (Micrometrics, Norcross, GA, USA) to determine surface area, pore-volume, and pore size distribution.

\section{Results and discussion}

\subsection{Characterization of the obtained porous parts}

The XRD analysis of the prepared CF-HAP (Fig. 1a), revealed the presence of pure and well-crystallized hexagonal hydroxyapatite $\mathrm{Ca}_{10}\left(\mathrm{PO}_{4}\right)_{6}(\mathrm{OH})_{2}$ based on the JCPDS database. The infra-red spectroscopy of the CF-HAP (Fig. 1b) showed only the presence of one well-crystallized phase of the hydroxyapatite. The observed IR absorption bands for the CF-HAP around 475, 575, 600, 960, 1040, and $1090 \mathrm{~cm}^{-1}$, are characteristic of the P-O group present in the theoretical hydroxyapatite, while other bands at 3572 and $632 \mathrm{~cm}^{-1}$ are referred to as the vibration of the hydroxyl groups $(\mathrm{OH})$ of the structure. The band detected at around $3500 \mathrm{~cm}^{-1}$ was attributed to the water adsorbed on the surface of the HAP foam. 

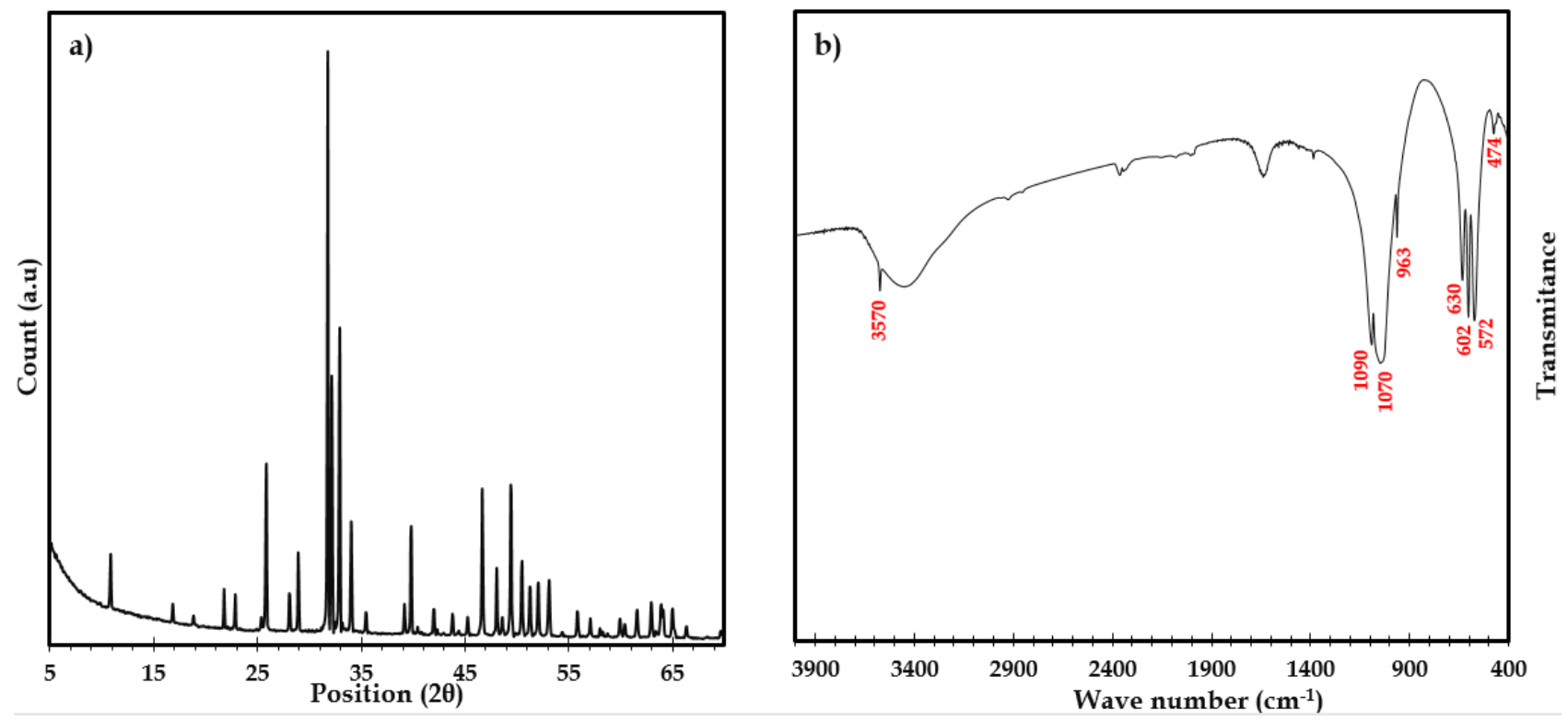

Fig. 1 a) XRD pattern and b) FTIR spectra of the sintered CF-HAP

It is visible in the SEM images (Fig. 2) that CF-HAP has an open and interconnected microstructure at different magnification scales. The images showed the presence of well-distributed pores on the surface

(Fig. 2 a-c) as well as inside the foams (Fig. 2 b-d).
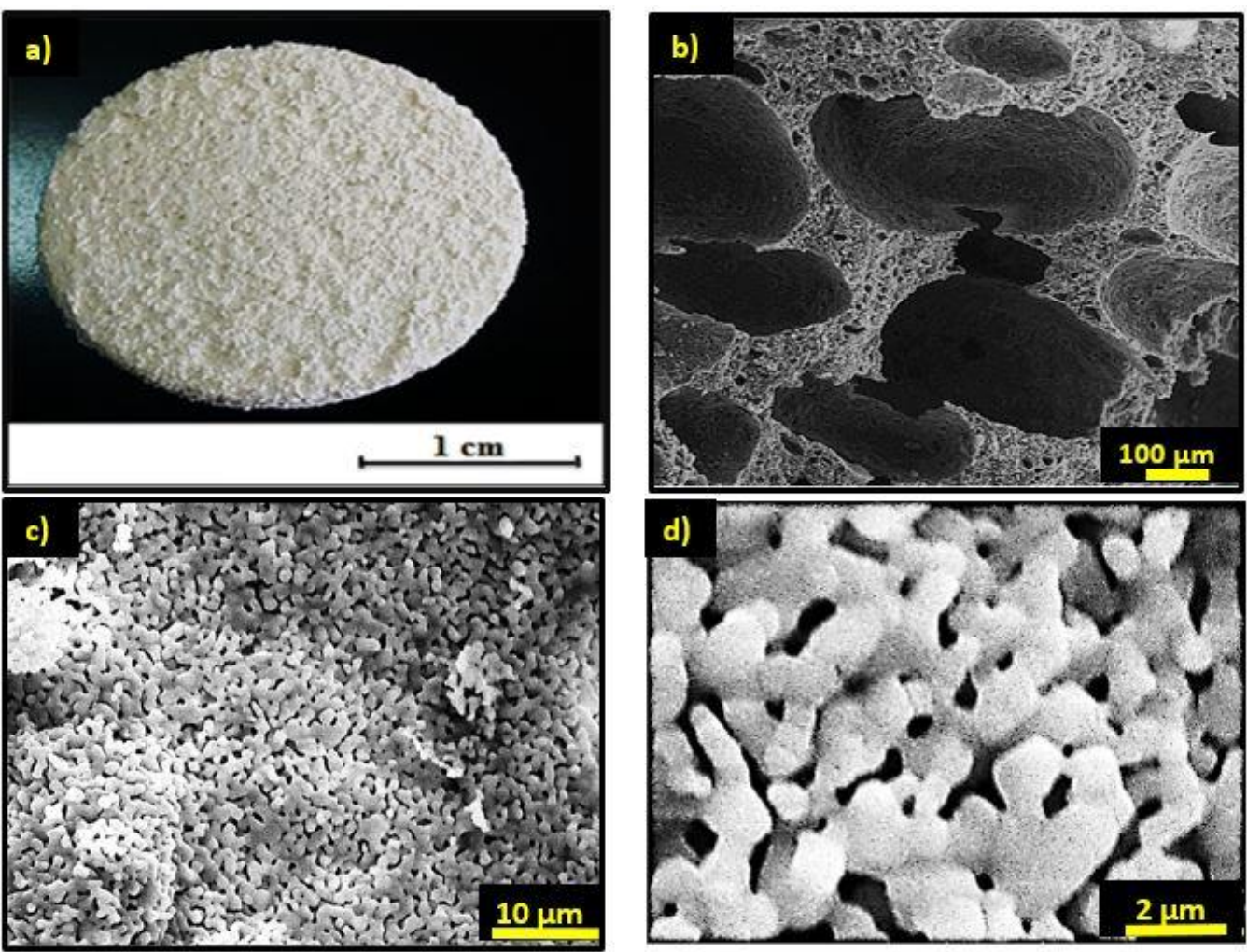

Fig. 2 a) CF-HAP as obtained, SEM images of b-c) the foam surface and d) the foam's inside

The pores were formed due to space created by air bubbles and also by the burning-out of the egg-protein as it was already discussed in our previous work (Khallok et al. 2019). The obtained CF-HAP has a wide variation in porosity and pore size from 1 to $650 \mu \mathrm{m}$ (Fig. 3d). The majority of the pores in the CF-HAP 
159 had size less than $100 \mu \mathrm{m}$ while two other populations of pores ranging from 100 to $300 \mu \mathrm{m}$ and from 160350 to $650 \mu \mathrm{m}$ present a minority.

161 Fig. 3a shows the adsorption-desorption isotherm of the CF-HAP. The curve shows an early initial monolayer coverage followed by multilayer formation with a well-defined hysteresis loop at around $\mathrm{p} / \mathrm{p}_{0}=0.89-0.98$, as observed in Fig. 3a. The presence of a wide hysteresis loop with a delay is probably due to the presence of the macropores in the CF-HAP. The presence of a loop in the hysteresis suggests that in addition to the macropores, the material contain also mesopores representing the Type IV adsorption isotherm with the $\mathrm{H}_{3}$ loop according to IUPAC classification. (Grosman and Ortega 2008). In fact, the BJH results show that CF-HAP has wide-ranging pore size distribution as presented in Fig. 3b. This result was in accordance with what was found earlier by M.F. Cipreste and all (Cipreste et al. 2016). CF-HAP had a specific surface area of $10 \mathrm{~m}^{2} \cdot \mathrm{g}^{-1}$, which is close to the calculated Langmuir surface area of $14 \mathrm{~m}^{2} \cdot \mathrm{g}^{-1}$. The distribution of mesopores ranges from 2 to $120 \mathrm{~nm}$ with an average pore size of $5.18 \mathrm{~nm}$ and a total pore volume of $0.013 \mathrm{~cm}^{3} \cdot \mathrm{g}^{-1}$ covering pores size less than $80 \mathrm{~nm}$ (Fig. 3c).
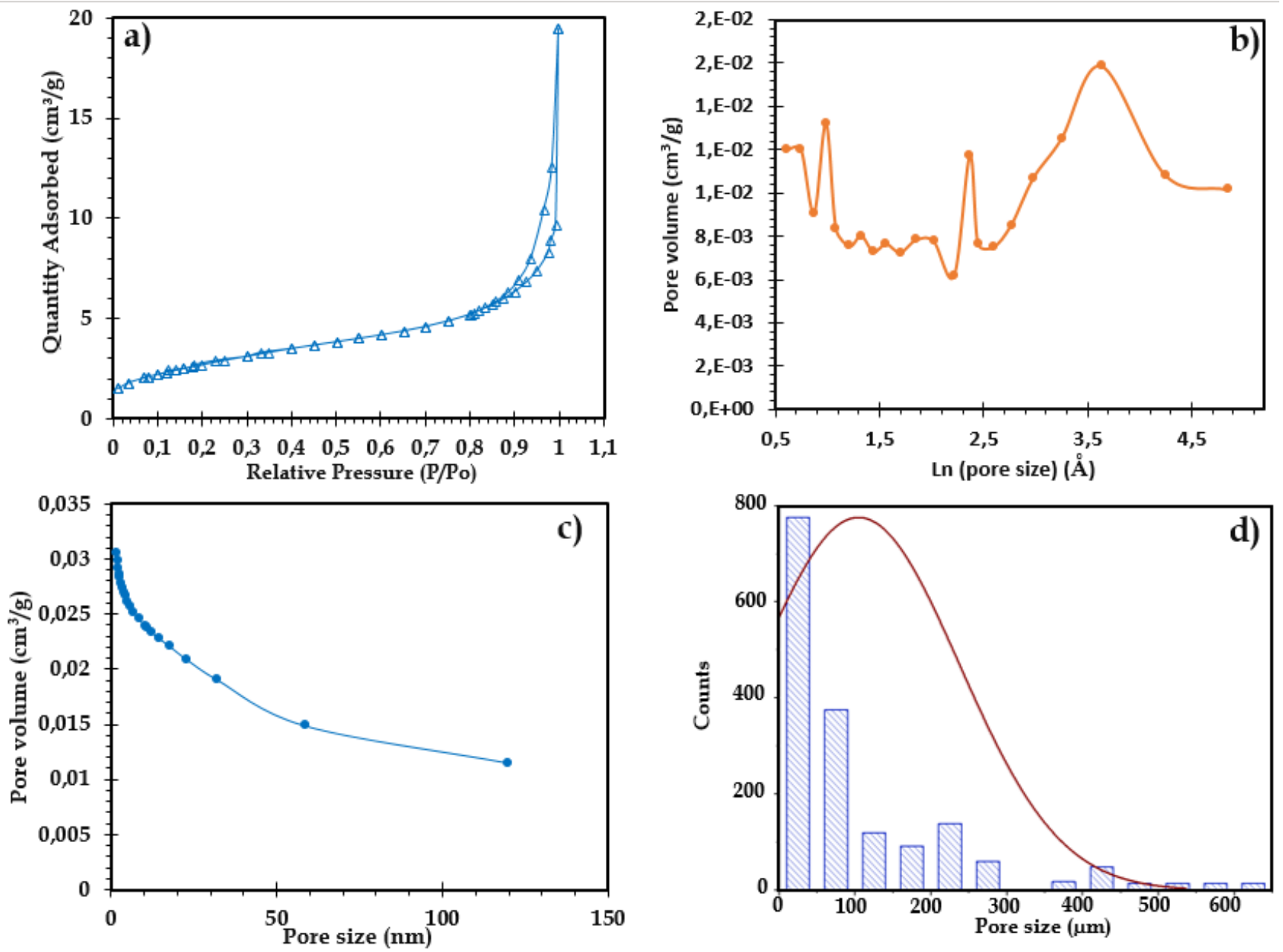

Fig. 3 a) Nitrogen adsorption-desorption curve, b) derived pore volume distribution, c) pore volume distribution and d) pore 


\subsubsection{The Effect of $\mathrm{pH}$}

178 The effect of initial $\mathrm{pH}$ on the adsorption capacity (equation (1)) of BPA was evaluated using $150 \mathrm{mg}$ of $179 \mathrm{CF}-\mathrm{HAP}$ and $40 \mathrm{mg} / \mathrm{L}$ of BPA at room temperature for 3 hours (Fig. 4). As shown, the removal (equation 180 (2)) was relatively constant (around $94 \%$ ) from pH 2 to 6.5. However, it decreased from 94 to $15 \%$ when the $\mathrm{pH}$ increased from 6.5 to 12 .

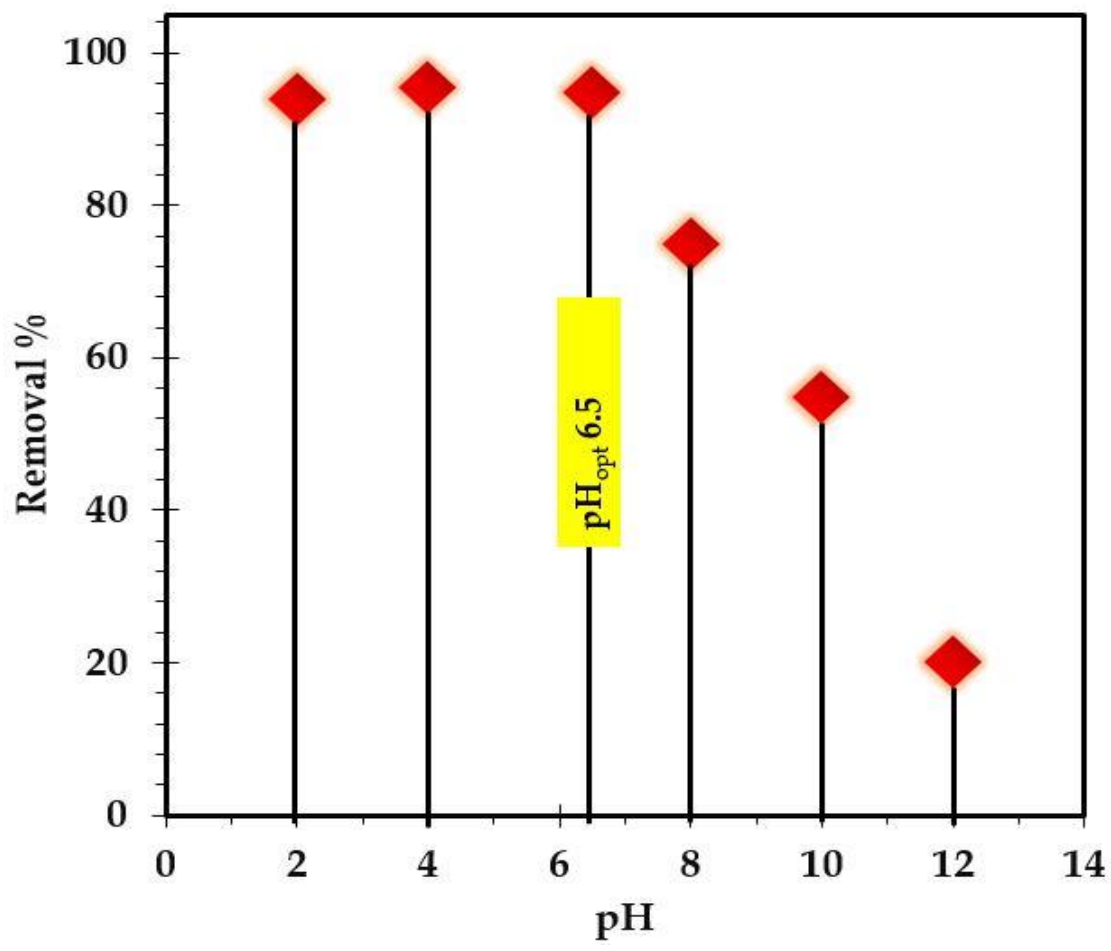

Fig. 4 Effect of initial $\mathrm{pH}$ on the adsorption efficiency of the CF-HAP

These results can be explained by the change in surface charge that occurs on the CF-HAP and/or by the nature of the BPA. In the lower $\mathrm{pH}$ region, the positively charged $\left(\mathrm{CaOH}^{2+}\right)$ and neutral $\equiv \mathrm{P}-\mathrm{OH}$ sites prevail on the CF-HAP surface, making the surface charge of CF-HAP positive ( Bouyarmane et al. 2010) as explained by equation (11):

$$
\equiv \mathrm{CaOH}+\mathrm{H}^{+} \longrightarrow \mathrm{Ca} \mathrm{OH}^{2+}
$$

In the basic medium neutral $(\mathrm{CaOH})$ and $\left(\mathrm{PO}^{-}\right)$species dominate, producing a negative charge on the surface of the CF-HAP according to equation (12):

$$
\equiv \mathrm{PO}^{-}+\mathrm{H}^{+} \longrightarrow \equiv \mathrm{POH}
$$

Thus, the point of zero charges $\left(\mathrm{pH}_{\mathrm{pzc}}\right)$ of $\mathrm{CF}-\mathrm{HAP}$ is the main parameter influencing the adsorption phenomenon. The $\mathrm{pH}_{\mathrm{pzc}}$ value of CF-HAP measured in this study was 6.7 as implied by many other 
studies (Bell et al. 1973; Bengtsson et al. 2009; Bouyarmane et al. 2010). When the solution pH is above the $\mathrm{pH}_{\mathrm{pzc}}$ the surface of the CF-HAP is negatively charged. The electrostatic repulsion occurs between the negatively charged surface of CF-HAP and the BPA in a form of mono-anion of bisphenolate at $\mathrm{pH}>$ 6.5, which explains the decrease of BPA adsorption (Zbair et al. 2018a). On the contrary, in the acidic range $\left(\mathrm{pH}<\mathrm{pH}_{\mathrm{pzc}}\right)$, the surface of CF-HAP is positively charged, and the BPA is under its neutral form, which does not favor electrostatic interactions and consequently maintains the relatively constant BPA adsorption. This suggests that other mechanisms than electrostatic attraction might be involved in BPA adsorption on CFHAP. These obtained results were similar to previous studies (Bautista-Toledo et al. 2005; Tsai et al. 2006a, b).

\subsubsection{Adsorption kinetics of BPA}

The kinetics of the BPA adsorption onto CF-HAP was assessed at three different initial concentrations (20, 30, and $40 \mathrm{mg} / \mathrm{L})$. As shown in Fig. 5, the BPA adsorption on CF-HAP occurred rapidly and at the initial $\mathrm{pH}$ of 6.5 , which was the $\mathrm{pH}$ of the prepared solution without adjustment, and the adsorption equilibrium was reached about 20 min.

The fast adsorption process may be related to the presence of the macropores that allow rapid and turbulent flow through the ceramic body enhancing the external diffusion from the solution to the surface of CF-HAP. The presence of interconnected pores ensures better adsorption efficiency, by trapping the molecules inside the foam for longer residence time, which enhances the adsorption efficiency. The FTIR analysis shows that the hydroxyapatite might have a strong affinity to BPA molecules in the solution since the CF-HAP after BPA adsorption shows that the bands of Bisphenol A were superposed on the spectrum of the hydroxyapatite with a shifting of some characteristic frequencies, as it will be shown later.

The pseudo-first order (PFO) (3), and pseudo-second order (PSO) (4) kinetic models were used to fit the kinetic data (Fig. 5). As can be seen from Table 2, the $\mathrm{R}^{2}$ values calculated for the PFO model were very close to $1\left(\mathrm{R}^{2}=0.999\right)$ while $\mathrm{R}^{2}$ obtained from the PSO model was lower than 0.996-0.997 depending on the initial concentration. The standard deviation (SD) (0.154-0.277) of the PFO model was lower than that of the PSO model (0.299-0.625). Therefore, the PFO model was able to explain the adsorption of BPA on CF-HAP at all studied initial concentrations. Similar results have been reported by several authors (Peng et al. 2015; Taghi et al. 2016). Furthermore, the adsorption capacities of BPA onto CF-HAP noticeably increased as the initial concentration of BPA increased (from $20 \mathrm{mg} / \mathrm{L}$ to $40 \mathrm{mg} / \mathrm{L}$ ). However, the adsorption rate $\mathrm{K}_{2}$ (g/mg.min) decreased as a function of initial concentration, with the following order: 0.742 (g/mg.min) at $20 \mathrm{mg} / \mathrm{L}>0.109$ (g/mg.min) for $30 \mathrm{mg} / \mathrm{L}>0.031$ (g/mg.min) for $40 \mathrm{mg} / \mathrm{L}$. The reason of this behavior may be due to the higher competition at the adsorption sites (Ouasfi et al. 2018). 


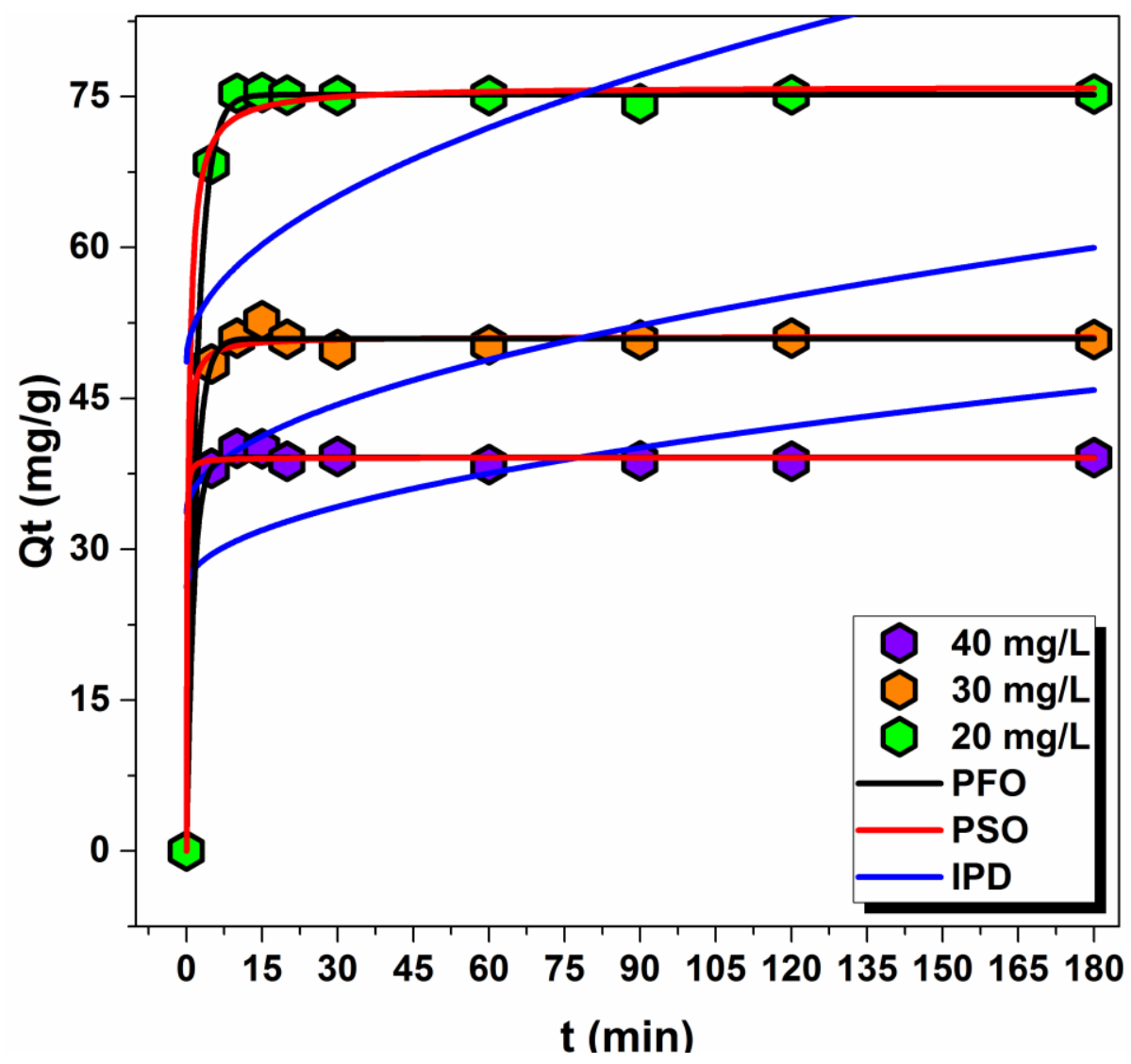

Fig. 5 Time evolution of the adsorption capacity. Kinetic study by PFO, PSO, and IPD models at 40ppm of BPA and at 298 K

To inspect the mechanism of BPA transfer on the surface of the CF-HAP and the rate-limiting step of the Bisphenol-A adsorption, the kinetic data were also fitted using the nonlinear intra-particle diffusion (IPD) model (5). The parameters determined for the IPD model of BPA adsorption onto CF-HAP are shown in Table 2. The $\mathrm{K}_{\text {ip }}$ (IPD rate constant) values were calculated to be $1.460,1.963$, and $3.003 \mathrm{mg} / \mathrm{g} . \mathrm{min}^{1 / 2}$ for the initial concentrations of 20,30, and $40 \mathrm{mg} / \mathrm{L}$, respectively. The plotted IPD model did not present a straight line passing through the origin (Fig. 5): this suggests that the intraparticle diffusion was not the only ratecontrolling step of the Bisphenol-A adsorption; in fact, these outcomes indicated that the adsorption of BPA on CF-HAP occurs in two stages: first via very fast surface adsorption and then by slow intraparticle diffusion.

Table 2 Pseudo-First-Order, Pseudo-Second Order, and intraparticle diffusion parameters for adsorption of BPA onto CFHAP

\begin{tabular}{ccccccc}
\hline & \multicolumn{2}{c}{ Pseudo-second Order (PSO) } & \multicolumn{3}{c}{ Pseudo-first Order (PFO) } \\
$\begin{array}{c}\mathbf{C}_{\text {intial }} \\
(\mathbf{m g} / \mathbf{L})\end{array}$ & $\mathbf{Q}_{\mathrm{e}, \text { cal }}(\mathbf{m g} / \mathbf{g})$ & $\mathbf{K}_{\mathbf{1}}\left(\mathbf{m i n}^{-\mathbf{1}}\right)$ & $\mathbf{R}^{2}$ & $\begin{array}{c}\mathbf{Q}_{\mathrm{e}, \mathrm{cal}} \\
(\mathbf{m g} / \mathbf{g})\end{array}$ & $\begin{array}{c}\mathbf{K}_{\mathbf{2}} \\
(\mathbf{g} / \mathbf{m g . m i n})\end{array}$ & $\mathbf{R}^{\mathbf{2}}$ \\
\hline $\mathbf{2 0}$ & $39.09 \pm 0.299$ & 0.742 & 0.997 & $39.14 \pm 0.201$ & 0.729 & 0.999 \\
$\mathbf{3 0}$ & $51.14 \pm 0.452$ & 0.109 & 0.996 & $50.94 \pm 0.277$ & 0.604 & 0.999
\end{tabular}




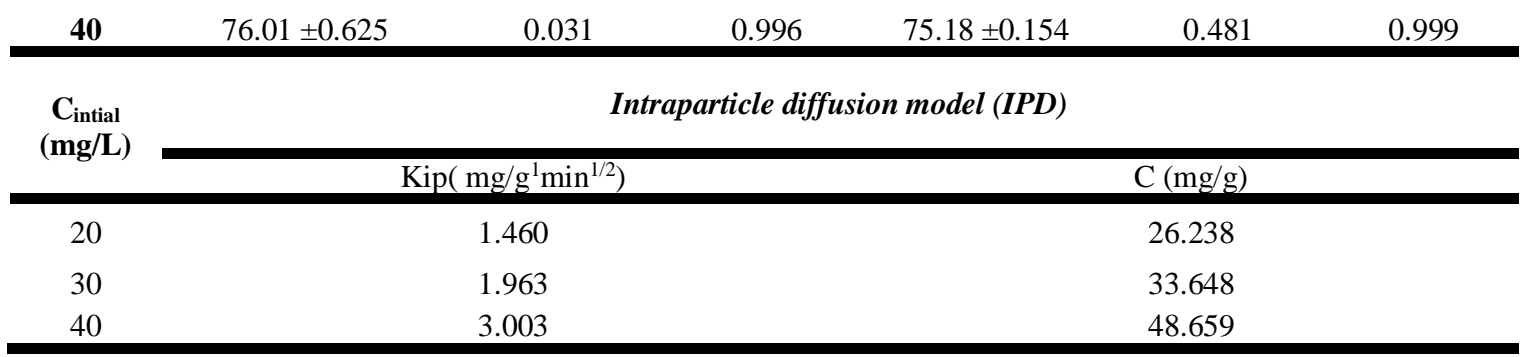

\subsubsection{BPA adsorption isotherm}

251 Adsorption isotherms are valuable in recognizing BPA and CF-HAP interactions. To clarify the 252 adsorption mechanism of BPA, Langmuir (6), Freundlich (7), and Liu (8) models were used to explain 253 the experimental data at 293, 303, and $313 \mathrm{~K}$ (Fig. 6).
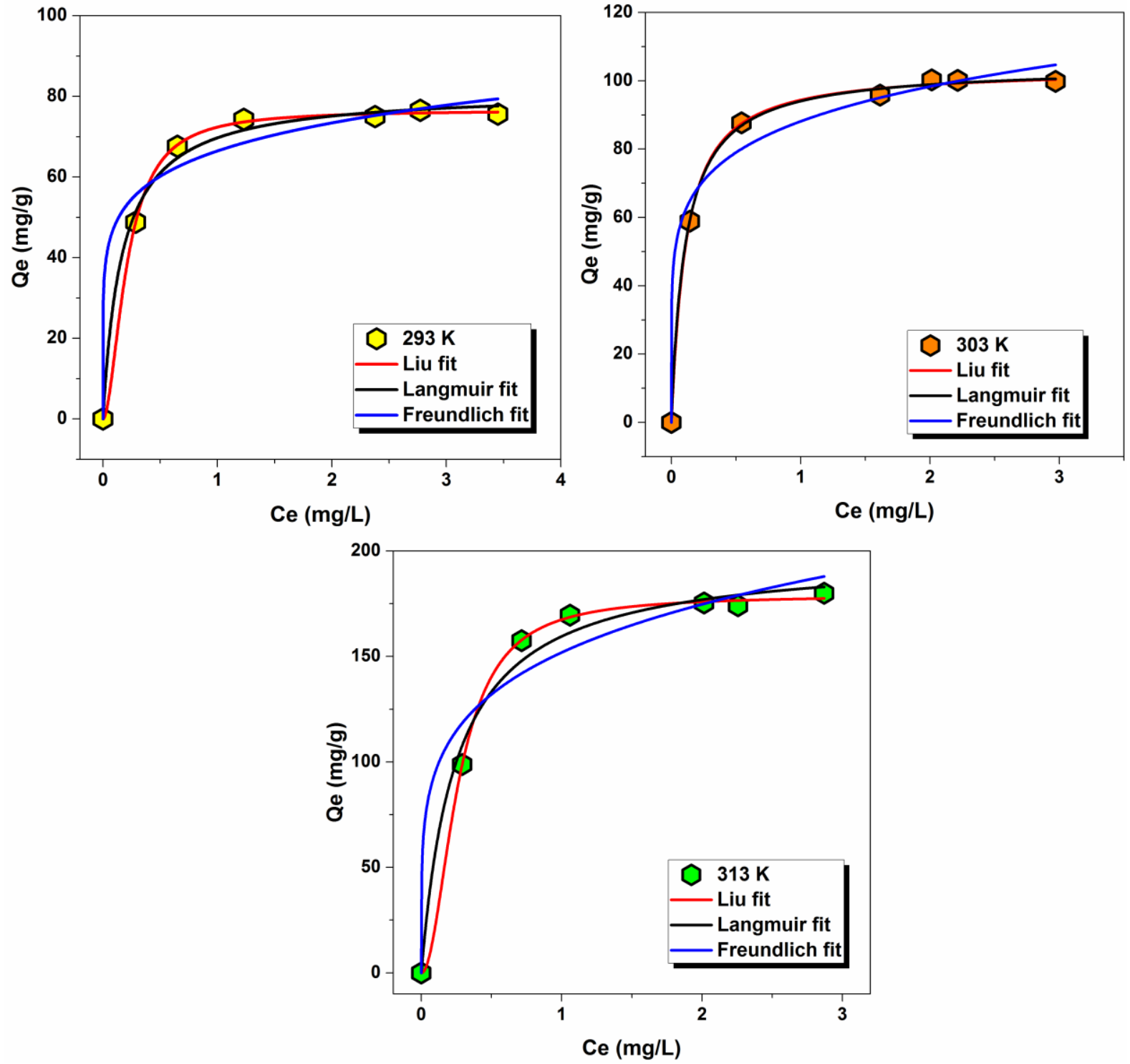

Fig. 6 Isotherm models of BPA adsorption over CF-HAP at different temperatures and at $\mathrm{pH}=6.5$

257 The adsorption parameters in Table 3 for Langmuir, Freundlich, and Liu models show the lowest SD 258 values, for the Liu model. The equilibrium concentration value $\left(\mathrm{Q}_{\mathrm{e}}\right)$ of Liu's model was closest to the 
experimentally measured $Q_{e}$. The Langmuir and the Freundlich models did not fit very well to the experimental data, giving the SD values ranging from 0.745 to 6.911 for Langmuir and 2.109-6.181 for Freundlich while the SD values obtained for the Liu model were $0.483-1.489$ and the $\mathrm{R}^{2}$ value was close to one. This proves that the experimental data fitted better with the Liu adsorption isotherm. This could be explained by the fact that the adsorption might occur in the hydroxyapatite sites, and also it depends on the nature of their interaction with the Bisphenol A. During the adsorption, the BPA interact strongly with the different functional groups of the hydroxyapatite namely the $\mathrm{OH}, \mathrm{Ca}^{2+}$ and $\mathrm{PO}_{4}$ as it was proved by the FTIR analysis (Fig. 8) and by earlier studies (H.Bouyarmane et al. 2010).

Table 3 Parameters of adsorption isotherms modeled by the Langmuir, Freundlich, and Liu models

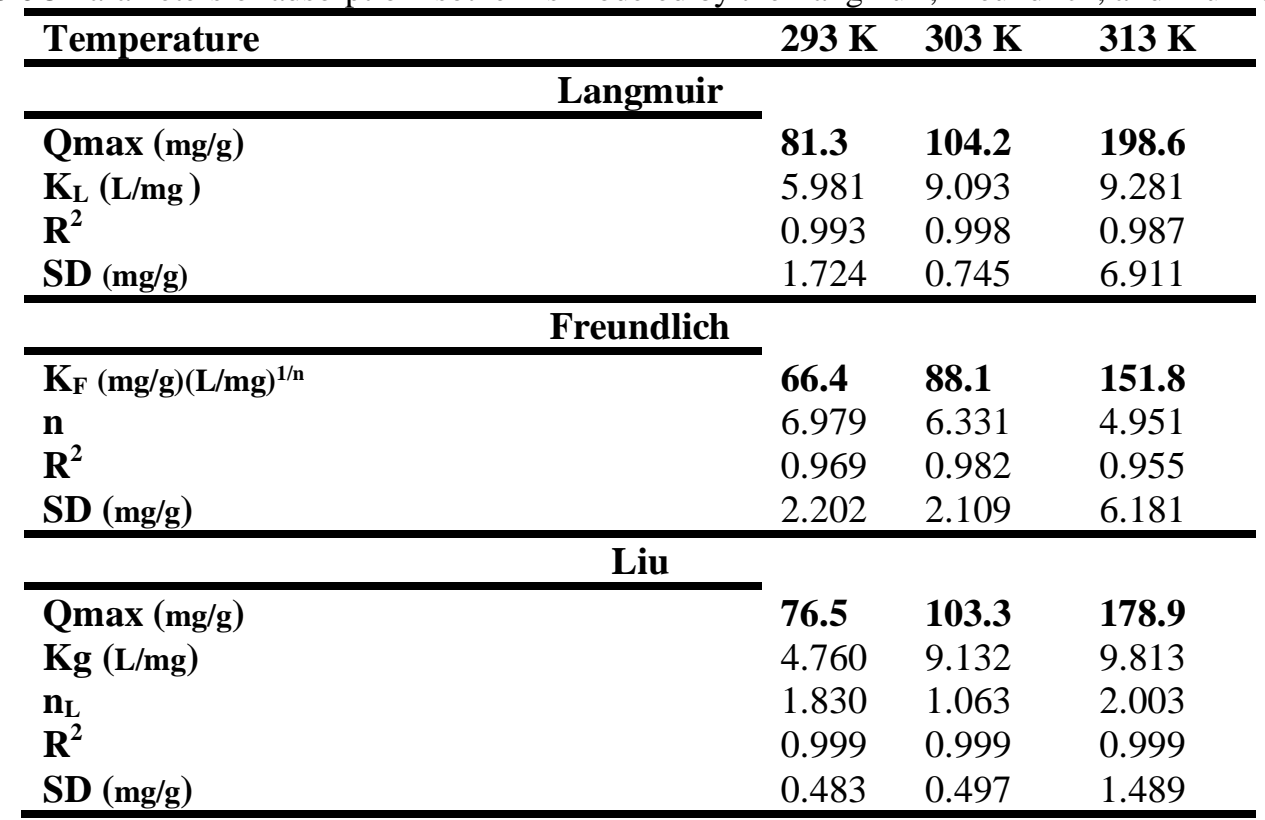

The effect of the temperature showed that the adsorption capacity increased when increasing the temperature; the maximum amounts of BPA adsorbed by CF-HAP were $76.5 \mathrm{mg} / \mathrm{g}$ at $293 \mathrm{~K}, 103.3 \mathrm{mg} / \mathrm{g}$ at $303 \mathrm{~K}$, and $178.9 \mathrm{mg} / \mathrm{g}$ at $313 \mathrm{~K}$. This result indicates that the removal of BPA from the solution was endothermic since the adsorption capacity increased with the temperature. The BPA adsorption capacity on the CF-HAP was compared with the adsorption capacities of various adsorbents. As shown in Table 4, the CF-HAP presented a good adsorption capacity compared to other materials including activated carbon (Qin et al. 2015) and graphene (Xu et al. 2012) that are known to have high adsorption capacity. 


\begin{tabular}{|c|c|c|c|c|c|c|}
\hline \multirow{2}{*}{ Adsorbents } & \multirow{2}{*}{$\begin{array}{l}\text { Qmax } \\
(\mathrm{mg} / \mathrm{g})\end{array}$} & \multicolumn{4}{|c|}{ Adsorption conditions } & \multirow{2}{*}{ References } \\
\hline & & $\begin{array}{c}\text { BPA } \\
\begin{array}{c}\text { Concentration } \\
(\mathrm{mg} / \mathbf{l})\end{array} \\
\end{array}$ & $\begin{array}{c}\text { Dose } \\
(\mathrm{g} / \mathrm{l})\end{array}$ & $\mathbf{p H}$ & $\mathbf{T}(\mathbf{K})$ & \\
\hline Activated carbon & 476 & 20 & 0.05 & 5.6 & 298 & $\begin{array}{l}\text { (El Ouahedy N et } \\
\text { al. 2020) }\end{array}$ \\
\hline $\begin{array}{l}\text { Mesoporous carbon (soft } \\
\text { template) }\end{array}$ & 156 & 10 & 0.1 & 6 & 302.15 & (Xu J et al. 2012) \\
\hline $\begin{array}{l}\text { HDTMA-sericite } \\
\left(\mathrm{CH}_{3}\left(\mathrm{CH}_{2}\right){ }_{15} \mathrm{~N}\left(\mathrm{CH}_{3}\right)_{3} \mathrm{Br}\right)\end{array}$ & 5.047 & 10 & 2 & 6.5 & 298 & $\begin{array}{l}\text { (Thanhmingliana } \\
\text { et al. 2014) }\end{array}$ \\
\hline $\begin{array}{l}\text { Mesoporous carbon (soft } \\
\text { template) }\end{array}$ & 156 & 30 & 0.1 & - & 298 & $\begin{array}{l}\text { (Libbrecht } W \text { et } \\
\text { al. 2015) }\end{array}$ \\
\hline $\begin{array}{l}\text { Commercial activated carbon } \\
\text { modified with nitric acid }\end{array}$ & 57.08 & 60 & 0.1 & 7 & 298 & $\begin{array}{l}\text { (Liu F et al. } \\
\text { 2009) }\end{array}$ \\
\hline Hydrophobic zeolite & 111.11 & 20 & 0.5 & 7 & 298 & $\begin{array}{l}\text { (Tsai W-T et al. } \\
\text { 2006a) }\end{array}$ \\
\hline CF-HAP & 178.9 & 40 & 0.75 & 6.5 & 313 & This work \\
\hline
\end{tabular}

\subsubsection{Thermodynamic parameters}

The thermodynamic parameters $\left(\Delta G^{\circ}, \Delta H^{\circ}\right.$, and $\left.\Delta S^{\circ}\right)$ of BPA adsorption can be determined via the Van't Hoff approach and Gibb's free energy equation (Tran et al. 2017; Lima et al. 2019). The determined thermodynamic parameters are represented in Table 5. The negative values of $G^{\circ}(-33.857 \mathrm{~kJ} / \mathrm{mol}$, $36.653 \mathrm{~kJ} / \mathrm{mol}$, and $-38.050 \mathrm{~kJ} / \mathrm{mol}$ ) show that the BPA sorption by CF-HAP was a spontaneous and favorable process at all the studied temperatures $(293 \mathrm{~K}, 303 \mathrm{~K}$, and $313 \mathrm{~K})$. This result is in agreement with the literature (Lin et al. 2009). Besides, the equilibrium constant $K_{\mathrm{g}}$ increased remarkably when the temperature was increased, which proposes that the BPA adsorption on the hydroxyapatite CF-HAP is more favorable at a higher temperature $(313 \mathrm{~K})$. As indicated in Table 5, the adsorption capacity $\mathrm{Q}_{\mathrm{m}}$ of the Liu model increased when the temperature of the adsorption medium is increased from $293 \mathrm{~K}$ to 313 $\mathrm{K}$; this was in accordance with the adsorption isotherm and the $\Delta \mathrm{H}$ values $(+27.813 \mathrm{~kJ} / \mathrm{mol})$ indicating that the BPA adsorption on the CF-HAP is endothermic in nature. The endothermic adsorption is attributed to chemical adsorption (chemisorption) with strong bonding of the adsorbate on the adsorbent. In contrast, in physisorption relatively weak interactions (i.e., Van Der Waals force) are involved. As a result, the adsorbate tends to desorb easily from the adsorbent surface when the temperature increases (Van et al. 2018). In the case of the Bisphenol A adsorption onto CF-HAP, the evaluated value of $\Delta \mathrm{H}^{\circ}$ was positive so that the adsorption process is endothermic in nature while the positive values of $\Delta S(0.211$ $\mathrm{kJ} / \mathrm{mol}$ ) show that the organization of BPA molecules at the solid/solution interface become more random when the temperature increases. 
Table 5 Thermodynamic parameters of the adsorption process of BPA onto the ceramic foam

\begin{tabular}{|c|c|c|c|c|}
\hline \multirow{3}{*}{$\Delta H(\mathbf{H J} / \mathrm{mol})$} & \multirow{3}{*}{$\Delta \mathbf{S}(\mathbf{k J} / \mathbf{m o l ~ K})$} & $293 \mathrm{~K}$ & $303 \mathrm{~K}$ & $313 \mathrm{~K}$ \\
\hline & & \multicolumn{3}{|c|}{$\left.\overline{K_{g}(L / m o l}\right)$} \\
\hline & & 1086643 & 2084710 & 2240173 \\
\hline & & \multicolumn{3}{|c|}{$\Delta G(\mathrm{~kJ} / \mathrm{mol})$} \\
\hline 27.813 & 0.211 & $-\mathbf{3 3 . 8 5 7}$ & -36.653 & -38.050 \\
\hline
\end{tabular}

\subsubsection{Regeneration of ceramic foam}

The regeneration and reuse of the CF-HAP are essential for an eco-friendly adsorbent. Thus, two consecutive regeneration tests were conducted (Fig. 7) using $40 \mathrm{~mL}$ of ethanol as the stripping agent. The adsorption of BPA at each run 1,2, and 3 were 94\%, 92\%, and 85\%, respectively, showing that the adsorption capacity was not fully recovered after used regeneration procedures. This was expected due to the chemisorption observed earlier. However, complete regeneration of the CF-HAP can be achieved using a calcination step as the foam present a high thermal stability up to $1200{ }^{\circ} \mathrm{C}$ as discussed in connection with the XRD and FTIR analyses.

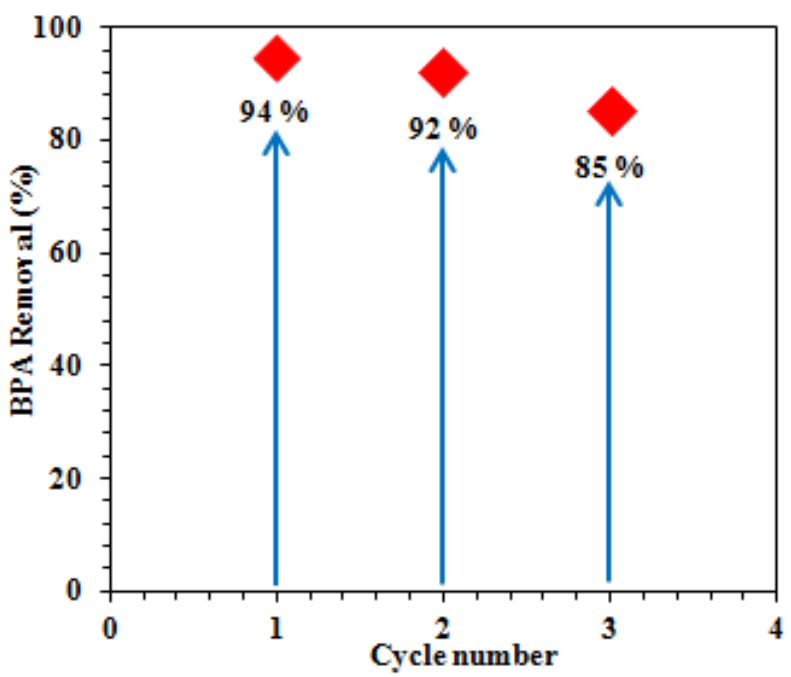

Fig. 7 BPA adsorption efficiency of the CF-HAP after two regeneration treatments: first initial BPA removal, second BPA removal after first regeneration, and third BPA removal after second regeneration

\subsubsection{Proposed mechanism}

In order to discover the adsorption mechanism of BPA on ceramic foam, the FTIR spectra of unused and used CF-HAP were compared. Fig. 8 shows that several new peaks appear in the FTIR spectrum of the CF-HAP after the BPA adsorption. These new peaks marked by yellow color $\left(1542-1149 \mathrm{~cm}^{-1}\right.$, $813 \mathrm{~cm}^{-1}$, and $528-401 \mathrm{~cm}^{-1}$ ) are related to the vibration peak of $\mathrm{C}=\mathrm{C}$ group in benzene ring of BPA 
molecule and appear with significant intensities, which proves BPA adsorption (Liu et al. 2018)(Jin et al. 2015). Moreover, the two peaks related to $-\mathrm{OH}$ groups were shifted from 3572 to $3568 \mathrm{~cm}^{-1}$ and 632 to $627 \mathrm{~cm}^{-1}$, which can refer to the creation of hydrogen binding between -OH groups of the BPA and of the hydroxyapatite foam. In fact, several works report that the adsorption of Bisphenol-A is based also in hydrogen bonding with the adsorbent as found earlier in the work of Chen (Chen and Chen 2015). The peaks that belong to P-O bonds were also shifted and their intensity decreased after BPA adsorption. From those results, we can conclude that $-\mathrm{OH}$ and $\mathrm{P}-\mathrm{O}$ groups are involved in the interaction between BPA and the surface of the ceramic foam. These findings demonstrate that the adsorption process of BPA on the CF-HAP was mainly due to chemisorption.

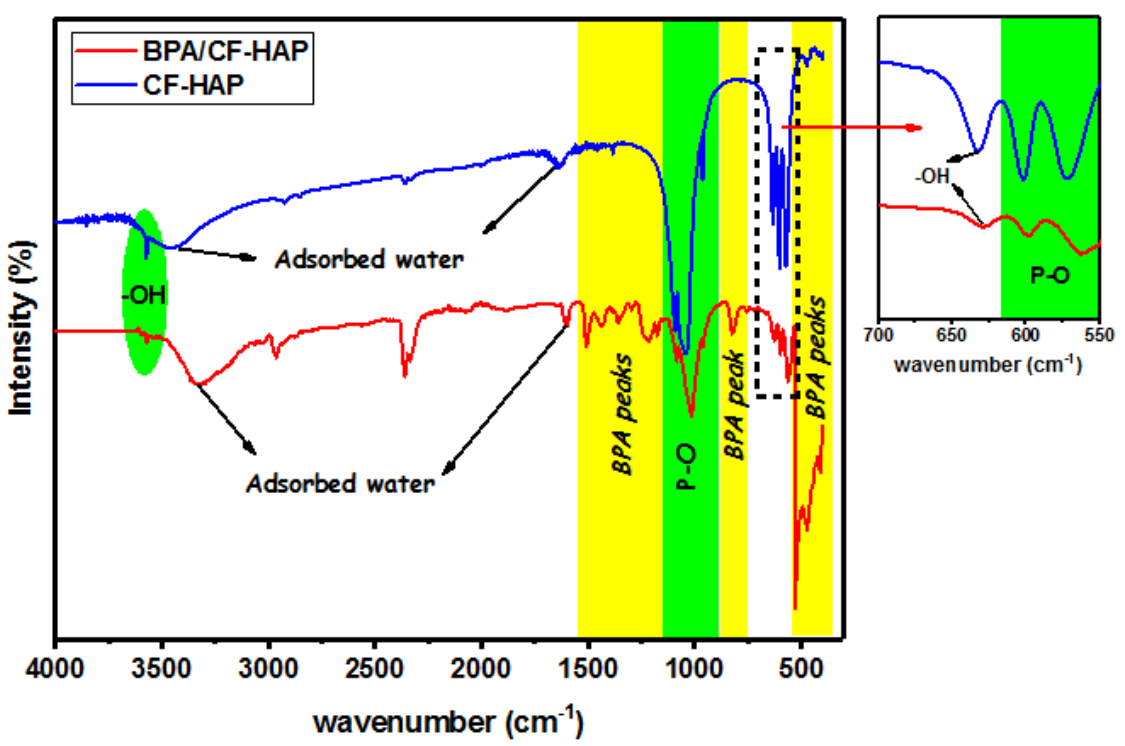

Fig. 8 FTIR spectra of CF-HAP before and after BPA adsorption at a pH of 6.5

The proposed adsorption mechanism (Fig. 9) is based on the results from the FTIR measurements and on an earlier study of Bouyarmane et al. (Bouyarmane et al. 2010). The adsorption was mainly due to the interaction of phenols with the different functional groups of the hydroxyapatite namely the $\mathrm{OH}, \mathrm{Ca}^{2+}$, and $\mathrm{PO}_{4}$. The oxygen atoms of the phenol might react through the Lewis acid-base interactions with the calcium site while the hydrogen groups of the Bisphenol- A could interact through hydrogen-hydrogen Van Der Waals bonds with the P-O and/or with the hydroxyl groups $(\mathrm{OH})$ of the hydroxyapatite as it was mentioned before (Bouyarmane et al. 2010). 


\section{Conclusion}

CF-HAP was successfully prepared by combining slip-casting and foaming methods. The characterization results showed that the obtained CF-HAP has a similar structure to a Hydroxyapatite with an interconnected porous microstructure with a large pore size distribution ranging from $1 \mu \mathrm{m}$ to $650 \mu \mathrm{m}$. The adsorption experiments showed that $94 \%$ of BPA $(40 \mathrm{mg} / \mathrm{L})$ was effectively removed from water by the CF-HAP. In fact, the adsorption capacity on CF-HAP increased by increasing temperature and the kinetics data obeyed the pseudo-first-order model. The isotherm data fitted slightly better with the Liu model than with Langmuir and Freundlich models while the thermodynamic parameters recommended that the adsorption was an endothermic process. In addition, the magnitude of enthalpy indicates chemisorption between the CF-HAP and BPA. Finally, from the adsorption results, it can be concluded that the ceramic foam-based hydroxyapatite has the potential to be used as an adsorbent to eliminate emergent contaminants from wastewaters.

\section{-Ethical Approval}

and Consent to Participate

Non-applicable

\section{-Consent for publication}

Non-applicable

\section{Availability of data and materials}

Non-applicable

\section{Competing interests}

The authors declare no conflict of interest

\section{Funding}


The research leading to these results has received funding from the Erasmus+ Global program between the University of Oulu, Finland, and the University of Chouailb Doukkali in Morocco under the grant agreement no 56101_KA107_2015_HE. Part of the research was carried out during the NO-WASTE project that received funding from the European Union Seventh Framework Programme (FP / 20072013) under the grant agreement no [PIRSES-GA-2012-317714].

\section{Author's contributions}

Hamza Khallok produced the foams. Mohamed Zbair conducted the adsorption experiments. Satu

Ojala Rachid Brahmi, Riitta L. Keiski, and Zineb Hatim reviewed the results and the work methodology. Hamza Khallok and Mohamed Zbair wrote the original draft preparation. Hamza Khallok and Mohamed Zbair wrote and analyzed the obtained results. Kaisu Ainassaari conducted and analyzed the material's surface. Satu Ojala, Zineb Hatim and Hamza Khallok conducted and analyzed the foam's morphology, structure, and composition.

\section{Acknowledgments}

The authors wish to express their gratitude to the mentioned Research Units for their contributions.

The XRD and FTIR analyses were done at Chouaib Doukkali University, Faculty of Sciences El Jadida in Morocco. The Surface area measurements and the adsorption tests were carried out in the

Environmental and Chemical Engineering unit of the University of Oulu, Finland. The FESEM analyses were carried out at the Center of Microscopy and Nanotechnology, of the University of Oulu, Finland.

\section{References}

Achelhi K, Masse S, Laurent G, et al (2010) Role of carboxylate chelating agents on the chemical, structural and textural properties of hydroxyapatite. Dalt Trans. Https://doi.org/10.1039/c0dt00251h

Aguiar JE, Cecilia JA, Tavares PAS, et al (2017) Adsorption study of reactive dyes onto porous clay heterostructures. Appl Clay Sci. Https://doi.org/10.1016/j.clay.2016.09.001

Anastopoulos I, Kyzas GZ (2016) Are the thermodynamic parameters correctly estimated in liquid-phase adsorption phenomena? J Mol Liq 218:174-185. Https://doi.org/https://doi.org/10.1016/j.molliq.2016.02.059

Authority EFS (2010) Statistical re-analysis of the Biel maze data of the Stump et al (2010) study: "Developmental neurotoxicity study of dietary bisphenol A in Sprague-Dawley rats.” EFSA J 8:1836. Https://doi.org/10.2903/j.efsa.2010.1836

Bautista-Toledo I, Ferro-García MA, Rivera-Utrilla J, et al (2005) Bisphenol A Removal from Water by Activated Carbon. Effects of Carbon Characteristics and Solution Chemistry. Environ Sci Technol 39:6246-6250. Https://doi.org/10.1021/es0481169

Becker K, Güen T, Seiwert M, et al (2009) geres IV: Phthalate metabolites and bisphenol A in urine of German children. Int J Hyg Environ Health 212:685-692. Https://doi.org/https://doi.org/10.1016/j.ijheh.2009.08.002

Bell LC, Posner AM, Quirk JP (1973) The point of zero charge of hydroxyapatite and fluorapatite in aqueous solutions. J Colloid Interface Sci. Https://doi.org/10.1016/0021-9797(73)90288-9

Bengtsson Å, Shchukarev A, Persson P, Sjöberg S (2009) A solubility and surface complexation study of a nonstoichiometric hydroxyapatite. Geochim Cosmochim Acta. Https://doi.org/10.1016/j.gca.2008.09.034

Beronius A, Rudén C, Håkansson H, Hanberg A (2010) Risk to all or none?: A comparative analysis of controversies in the health risk assessment of Bisphenol A. Reprod Toxicol 29:132-146.

Https://doi.org/https://doi.org/10.1016/j.reprotox.2009.11.007

Bhatnagar A, Anastopoulos I (2017) Adsorptive removal of bisphenol A (BPA) from aqueous solution: A review. Chemosphere 
Chen X, Chen B (2015) Macroscopic and spectroscopic investigations of the adsorption of nitroaromatic compounds on graphene oxide, reduced graphene oxide, and graphene nanosheets. Environ Sci Technol. Https://doi.org/10.1021/es5054946

Ciobanu G, Ignat D, Carja G, Luca C (2009) Hydroxyapatite/polyurethane composite membranes for lead ions removal. In: Environmental Engineering and Management Journal

Cipreste MF, Peres AM, Cotta AAC, et al (2016) Synthesis and characterization of 159Gd-doped hydroxyapatite nanorods for bioapplications as theranostic systems. Mater Chem Phys. Https://doi.org/10.1016/j.matchemphys.2016.06.063

Dehghani MH, Ghadermazi M, Bhatnagar A, et al (2016) Adsorptive removal of endocrine disrupting bisphenol A from aqueous solution using chitosan. J Environ Chem Eng 4:2647-2655. Https://doi.org/https://doi.org/10.1016/j.jece.2016.05.011

El Ouahedy N, Zbair M, Ojala S, et al (2020) Porous carbon materials derived from olive kernels: application in adsorption of organic pollutants. Environ Sci Pollut Res. Https://doi.org/10.1007/s11356-020-09268-0

Elouahli A, Zbair M, Anfar Z, et al (2018) Apatitic tricalcium phosphate powder: High sorption capacity of hexavalent chromium removal. Surfaces and Interfaces 13:139-147. Https://doi.org/https://doi.org/10.1016/j.surfin.2018.09.006

Freundlich H (1907) Über die Adsorption in Lösungen. Zeitschrift für Phys Chemie 57U: https://doi.org/10.1515/zpch1907-5723

Ghosal PS, Gupta AK (2017) Determination of thermodynamic parameters from Langmuir isotherm constant-revisited. J Mol Liq 225:137-146. Https://doi.org/https://doi.org/10.1016/j.molliq.2016.11.058

Grosman A, Ortega C (2008) Capillary condensation in porous materials. Hysteresis and interaction mechanism without pore blocking/percolation process. Langmuir. Https://doi.org/10.1021/la703978v

Gu Y, Yu J, Hu X, Yin D (2016) Characteristics of the alkylphenol and bisphenol A distributions in marine organisms and implications for human health: A case study of the East China Sea. Sci Total Environ 539:460-469. Https://doi.org/https://doi.org/10.1016/j.scitotenv.2015.09.011

H.Bouyarmane, Asri SE, Rami A, et al (2010) Pyridine and phenol removal using natural and synthetic apatites as low cost sorbents: Influence of porosity and surface interactions. J Hazard Mater 181:736-741. Https://doi.org/https://doi.org/10.1016/j.jhazmat.2010.05.074

Huang YQ, Wong CKC, Zheng JS, et al (2012) Bisphenol A (BPA) in China: A review of sources, environmental levels, and potential human health impacts. Environ Int 42:91-99. Https://doi.org/https://doi.org/10.1016/j.envint.2011.04.010

Im J, Löffler FE (2016) Fate of Bisphenol A in Terrestrial and Aquatic Environments. Environ Sci Technol 50:8403-8416. Https://doi.org/10.1021/acs.est.6b00877

Inagaki M (2009) Pores in carbon materials-Importance of their control. Xinxing Tan Cailiao/ New Carbon Mater. Https://doi.org/10.1016/S1872-5805(08)60048-7

Inagaki M, Kang F (2014) Materials Science and Engineering of Carbon: Fundamentals: Second Edition

Jin Z, Wang X, Sun Y, et al (2015) Adsorption of 4- n -Nonylphenol and Bisphenol-A on Magnetic Reduced Graphene Oxides: A Combined Experimental and Theoretical Studies. Environ Sci Technol. Https://doi.org/10.1021/acs.est.5b02022

Kakoi B, Kaluli JW, Ndiba P, Thiong'o G (2016) Banana pith as a natural coagulant for polluted river water. Ecol Eng 95:699-705. Https://doi.org/https://doi.org/10.1016/j.ecoleng.2016.07.001

Kantharia N, Naik S, Apte S, et al (2014) Nano-hydroxyapatite and its contemporary applications. Bone 34:1-71

Kapelewska J, Kotowska U, Wiśniewska K (2016) Determination of personal care products and hormones in leachate and groundwater from Polish MSW landfills by ultrasound-assisted emulsification microextraction and GC-MS. Environ Sci Pollut Res. Https://doi.org/10.1007/s11356-015-5359-9

Khallok H, Ojala S, Ezzahmouly M, et al (2019) Porous foams based hydroxyapatite prepared by direct foaming method using egg white as a pore promoter. J Aust Ceram Soc 55:611-619. Https://doi.org/10.1007/s41779-018-0269-1

Kongsri S, Janpradit K, Buapa K, et al (2013) Nanocrystalline hydroxyapatite from fish scale waste: Preparation, characterization and application for selenium adsorption in aqueous solution. Chem Eng $\mathrm{J}$. Https://doi.org/10.1016/j.cej.2012.11.054

Langmuir I (1916) The constitution and fundamental properties of solids and liquids. Part I. Solids. J Am Chem Soc 38:2221-2295. Https://doi.org/10.1021/ja02268a002

Libbrecht W, Vandaele K, De Buysser K, et al (2015) Tuning the Pore Geometry of Ordered Mesoporous Carbons for Enhanced Adsorption of Bisphenol-A. Materials (Basel). 8:1652-1665

Lima EC, Hosseini-Bandegharaei A, Moreno-Piraján JC, Anastopoulos I (2019) A critical review of the estimation of the thermodynamic parameters on adsorption equilibria. Wrong use of equilibrium constant in the Van't Hoof equation for calculation of thermodynamic parameters of adsorption. J Mol Liq 273:425-434. Https://doi.org/https://doi.org/10.1016/j.molliq.2018.10.048

Lin K, Pan J, Chen Y, et al (2009) Study the adsorption of phenol from aqueous solution on hydroxyapatite nanopowders. J Hazard Mater. Https://doi.org/10.1016/j.jhazmat.2008.03.076

Liu F, Dai Y, Zhang S, et al (2018) Modification and application of mesoporous carbon adsorbent for removal of endocrine disruptor bisphenol A in aqueous solutions. J Mater Sci. Https://doi.org/10.1007/s10853-017-1705-2

Liu G, Ma J, Li X, Qin Q (2009) Adsorption of bisphenol A from aqueous solution onto activated carbons with different modification treatments. J Hazard Mater 164:1275-1280. 
Https://doi.org/http://dx.doi.org/10.1016/j.jhazmat.2008.09.038

Mavropoulos E, Costa AM, Costa LT, et al (2011) Adsorption and bioactivity studies of albumin onto hydroxyapatite surface. Colloids Surfaces B Biointerfaces. Https://doi.org/10.1016/j.colsurfb.2010.10.025

Mckay G (1999) Pseudo-second order model for sorption processes. Proc Biochem 34:451

Mourabet M, El Rhilassi A, El Boujaady H, et al (2015) Removal of fluoride from aqueous solution by adsorption on hydroxyapatite (hap) using response surface methodology. J Saudi Chem Soc. Https://doi.org/10.1016/j.jscs.2012.03.003

Narwade VN, Khairnar RS, Kokol V (2017) In-situ synthesised hydroxyapatite-loaded films based on cellulose nanofibrils for phenol removal from wastewater. Cellulose 24:4911-4925. Https://doi.org/10.1007/s10570-017-1435-2

Noukeu NA, Gouado I, Priso RJ, et al (2016) Characterization of effluent from food processing industries and stillage treatment trial with Eichhornia crassipes (Mart.) And Panicum maximum (Jacq.). Water Resour Ind 16:1-18. Https://doi.org/10.1016/j.wri.2016.07.001

Oliveira M, Mansur HS (2007) Synthetic tooth enamel: SEM characterization of a fluoride hydroxyapatite coating for dentistry applications. Mater Res 10:115-118

Ouasfi N, Bouzekri S, Zbair M, et al (2018) Carbonaceous Material Prepared by Ultrasonic Assisted Pyrolysis from Algae (Bifurcaria bifurcata): Response Surface Modeling of Aspirin Removal. Surfaces and Interfaces. Https://doi.org/https://doi.org/10.1016/j.surfin.2018.11.008

Peng S, Hao K, Han F, et al (2015) Enhanced removal of bisphenol-AF onto chitosan-modified zeolite by sodium cholate in aqueous solutions. Carbohydr Polym 130:364-371. Https://doi.org/10.1016/j.carbpol.2015.05.019

Pereira MBB, França DB, Araújo RC, et al (2020) Amino hydroxyapatite/chitosan hybrids reticulated with glutaraldehyde at different ph values and their use for diclofenac removal. Carbohydr Polym. Https://doi.org/10.1016/j.carbpol.2020.116036

Qin F-X, Jia S-Y, Liu Y, et al (2015) Adsorptive removal of bisphenol A from aqueous solution using metal-organic frameworks. Desalin Water Treat 54:93-102. Https://doi.org/10.1080/19443994.2014.883331

Ronan K, Kannan MB (2017) Novel Sustainable Route for Synthesis of Hydroxyapatite Biomaterial from Biowastes. ACS Sustain Chem Eng. Https://doi.org/10.1021/acssuschemeng.6b02515

Salah TA, Mohammad AM, Hassan MA, El-Anadouli BE (2014) Development of nano-hydroxyapatite/chitosan composite for cadmium ions removal in wastewater treatment. J Taiwan Inst Chem Eng 45:1571-1577. Https://doi.org/https://doi.org/10.1016/j.jtice.2013.10.008

Saucier C, Adebayo MA, Lima EC, et al (2015) Comparison of a Homemade Bacuri Shell Activated Carbon With Carbon Nanotubes for Food Dye Removal. CLEAN - Soil, Air, Water 43:1389-1400. Https://doi.org/10.1002/clen.201400669

Taghi M, Shokoohi R, Poormohammadi A, et al (2016) Removal of Bisphenol, Using Antimony Nanoparticle Multi-walled Carbon Nanotubes Composite from Aqueous Solutions. Orient J Chem 32:1015-1024. Https://doi.org/10.13005/ojc/320227

Thanhmingliana, Lee SM, Tiwari D (2014) Use of hybrid materials in the decontamination of bisphenol A from aqueous solutions. RSC Adv 4:43921-43930. Https://doi.org/10.1039/C4RA06793B

Tran HN, You SJ, Hosseini-Bandegharaei A, Chao HP (2017) Mistakes and inconsistencies regarding adsorption of contaminants from aqueous solutions: A critical review. Water Res 120:88-116. Https://doi.org/10.1016/j.watres.2017.04.014

TSAI W-T (2006) Human Health Risk on Environmental Exposure to Bisphenol-A: A Review. J Environ Sci Heal Part C 24:225-255. Https://doi.org/10.1080/10590500600936482

Tsai W-T, Hsu H-C, Su T-Y, et al (2006a) Adsorption characteristics of bisphenol-A in aqueous solutions onto hydrophobic zeolite. J Colloid Interface Sci 299:513-519. Https://doi.org/http://doi.org/10.1016/j.jcis.2006.02.034

Tsai W-T, Lai C-W, Su T-Y (2006b) Adsorption of bisphenol-A from aqueous solution onto minerals and carbon adsorbents. J Hazard Mater 134:169-175. Https://doi.org/http://dx.doi.org/10.1016/j.jhazmat.2005.10.055

Umar M, Roddick F, Fan L, Aziz HA (2013) Application of ozone for the removal of bisphenol A from water and wastewater - A review. Chemosphere 90:2197-2207. Https://doi.org/https://doi.org/10.1016/j.chemosphere.2012.09.090

Van HT, Nguyen LH, Nguyen VD, et al (2018) Characteristics and mechanisms of cadmium adsorption onto biogenic aragonite shells-derived biosorbent: Batch and column studies. J Environ Manage. Https://doi.org/https://doi.org/10.1016/j.jenvman.2018.09.079

Wang J, Huang CP, Allen HE, et al (1998) Adsorption characteristics of dye onto sludge particulates. J Colloid Interface Sci 208:518-528. Https://doi.org/10.1006/jcis.1998.5875

Wang X, Hu Y, Min J, et al (2018) Adsorption Characteristics of Phenolic Compounds on Graphene Oxide and Reduced Graphene Oxide: A Batch Experiment Combined Theory Calculation. Appl. Sci. 8

Wang X, Qin Y, Zhu L, Tang H (2015) Nitrogen-Doped Reduced Graphene Oxide as a Bifunctional Material for Removing Bisphenols: Synergistic Effect between Adsorption and Catalysis. Environ Sci Technol 49:6855-6864. Https://doi.org/10.1021/acs.est.5b01059

Weber, W.J. and Morris JC (1963) Kinetics of adsorption carbon from solutions. J Sanit Engeering Div Proceedings Am Soc Civ Eng 89:31-60

Xu J, Wang L, Zhu Y (2012) Decontamination of bisphenol A from aqueous solution by graphene adsorption. Langmuir 
Yüksel S, Kabay N, Yüksel M (2013) Removal of bisphenol A (BPA) from water by various nanofiltration (NF) and reverse osmosis (RO) membranes. J Hazard Mater 263:307-310.

Https://doi.org/https://doi.org/10.1016/j.jhazmat.2013.05.020

Zacharewski T (1998) Identification and assessment of endocrine disruptors: limitations of in vivo and in vitro assays. Environ Health Perspect 106:577-582. Https://doi.org/10.1289/ehp.98106577

Zbair M, Ainassaari K, Drif A, et al (2018a) Toward new benchmark adsorbents: preparation and characterization of activated carbon from argan nut shell for bisphenol A removal. Environ Sci Pollut Res 25:1869-1882. Https://doi.org/10.1007/s11356-017-0634-6

Zbair M, Ainassaari K, El Assal Z, et al (2018b) Steam activation of waste biomass: highly microporous carbon, optimization of bisphenol A, and diuron adsorption by response surface methodology. Environ Sci Pollut Res. Https://doi.org/10.1007/s11356-018-3455-3

Zbair M, Anfar Z, Ait Ahsaine H, Khallok H (2019) Kinetics, equilibrium, statistical surface modeling and cost analysis of paraquat removal from aqueous solution using carbonated jujube seed. RSC Adv. Https://doi.org/10.1039/c8ra09337g

Zhao J, Lu Z, He X, et al (2017) Fabrication and Characterization of Highly Porous Fe(OH) 3 @ Cellulose Hybrid Fibers for Effective Removal of Congo Red from Contaminated Water. ACS Sustain Chem Eng. Https://doi.org/10.1021/acssuschemeng.7b01175

Zielinska M, Wojnowska-Baryla I, Cydzik-Kwiatkowska a(2018) Biological Wastewater Treatment Technologies fro BPA Removal. Bisphenol A Remov. From Water Waswater 79-101 